\title{
Comparison of biofilm formation between non- pathogenic Listeria strains under different stress conditions
}

\author{
ENDRIT HASANI $^{1 *}$ (D), SABRINE LABIDI ${ }^{2}$, CSILLA MOHÁCSI-FARKAS ${ }^{2}$ and \\ GABRIELLA KISKÓ ${ }^{2}$
}

${ }^{1}$ Department of Refrigeration and Livestock Products Technology, Faculty of Food Science, Szent István University, Gödöllö, Hungary

${ }^{2}$ Department of Microbiology and Biotechnology, Faculty of Food Science, Szent István University, Gödöllö, Hungary

\section{CONFERENCE FULL PAPER}

Received: August 13, 2020 • Accepted: September 26, 2020

Published online: November 12, 2020

(C) 2020 The Author(s)

\section{ABSTRACT}

Micro-organisms can attach to food surfaces and develop biofilms which present a concern in food and environmental safety. The main goal of the current study was to investigate the biofilm formation of six non-pathogenic Listeria strains under different stress conditions using a microplate assay. The effect of the weak biofilm-forming non-pathogenic Listeria strains on the biofilm formation of a strong biofilm-forming pathogenic Listeria strain (Listeria monocytogenes \#8) was also examined. Listeria innocua CCM4030, Listeria innocua 2885 and Listeria seeligeri/welshimeri 292 showed the same patterns of biofilm formation with increasing $\mathrm{NaCl}$ concentrations from 0.05 to $15 \%$, but all the other strains showed a continuously decreasing trend of $\mathrm{OD}_{595}$ in the same conditions. This study showed that in the case of non-pathogenic Listeria strains, higher concentrations of $\mathrm{NaCl}$ do not present a stress condition that enhances biofilm formation. Decrease in $\mathrm{pH}$ inhibited biofilm formation for all the nonpathogenic Listeria strains. The weak biofilm forming non-pathogenic Listeria strains (Listeria innocua 2885 and Listeria innocua CCM4030) overgrew the strong biofilm-forming Listeria strain (Listeria monocytogenes \#8) during biofilm formation. This phenomenon could be beneficial and potentially be used as a novel control strategy to prevent the colonization of the pathogenic Listeria at food processing facilities such as in meat industry.

*Corresponding author. E-mail: endrithasani96@gmail.com 


\section{KEYWORDS}

$\mathrm{pH}$ stress, salt stress, Listeria innocua, Listeria monocytogenes, Listeria seeligeri/welshimeri

\section{INTRODUCTION}

Food-borne diseases present a major problem throughout the world causing thousands of deaths each year from the consumption of food and water contaminated with toxins and pathogens. Contamination of food can occur at any point in the food chain, from the raw material to the consumers' table. Pathogens can enter and contaminate the food system through humans, animals, air, water, soil, and contaminated equipment. The increased level of knowledge on how, where, and when the contamination of food happens and how preventive measures should be applied to present a necessity for the food safety of the products we consume in our everyday life (Zaukuu et al., 2016).

Listeria species are widespread in the environment including in soil, raw foods, stream water, silage, sewage, plants, and animals. However, Listeria monocytogenes is a ubiquitous pathogen that can cause infections in humans, thus representing a major concern for public health and economic aspect. Listeria species commonly colonize the food processing environment and ready-to-eat products. Ready-to-eat foods (RTE) are products consumed without any heattreatment and are usually associated with listeriosis outbreaks (Martín et al., 2014; Rückerl et al., 2014). Novel nonthermal decontamination technologies, like high hydrostatic pressure treatment, have been recognized to have a positive effect on Listeria monocytogenes inactivation and preserve the quality attributes of RTE foods (Bajovic et al., 2012; Dalmadi et al., 2007).

However, elimination of this bacterium from ready-to-eat foods and food processing equipment is difficult. The main reason is because of the ability of this bacterium to form biofilms that protect it from stresses in food processing environments. The difficulty of biofilm removal is also due to the increased resistance against disinfectants caused by factors such as the age of biofilm and different stress responses (Di Ciccio et al., 2012; Van Houdt and Michiels, 2010). Environmental factors, including temperature, sugar, salt, $\mathrm{pH}$, and nutrients, have been demonstrated to have impacts on the adhesion and biofilm formation of Listeria species in food (Renner and Weibel, 2011). To understand the susceptibility of Listeria species biofilms to different stress conditions, six biofilm-forming non-pathogenic Listeria strains were analyzed. The effect of the weak biofilm forming non-pathogenic Listeria strains on the biofilm formation of the strong biofilm-forming Listeria monocytogenes \#8 was also examined. There are knowledge-gaps in literature for this particular topic, therefore the importance of this study lies in the possibility to develop new methods to control biofilm formation in the food industry and increase the knowledge on the role of the harmless bacteria in the food safety.

\section{MATERIALS AND METHODS}

\section{Culture preparation}

A total of 7 previously identified Listeria strains were isolated from various sources and included in this study (Table 1). All the isolates were obtained in a previous study at the Department of Microbiology and Biotechnology, Faculty of Food Science, Szent István University, Budapest, 
Table 1. Listeria species used in this study

\begin{tabular}{lc}
\hline Species & Strains \\
\hline Listeria innocua & CCM4030 \\
Listeria innocua & 2885 \\
Listeria seeligeri/welshimeri & 292 \\
Listeria welshimeri & CCM3971 \\
Listeria ivanovii & 204 \\
Listeria denitrificans & 1157 \\
Listeria monocytogenes & $\# 8$ \\
\hline
\end{tabular}

Hungary. The different bacteria strains were stored at $-80{ }^{\circ} \mathrm{C}$ in a mixture of tryptic soy broth (TSB) and glycerol. They were later recovered on Brain Heart Infusion (BHI) Agar, cultivated at $37{ }^{\circ} \mathrm{C}$ for $24-48 \mathrm{~h}$ and then streaked onto Trypto-Casein Soy Agar (TSA) before cultivating again at $37{ }^{\circ} \mathrm{C}$ for $24 \mathrm{~h}$.

\section{Culture media}

Components of M9 Minimal Media $\left(\mathrm{NH}_{4} \mathrm{Cl}\left[1.9 \mathrm{mM}\right.\right.$ ], $\mathrm{Na}_{2} \mathrm{HPO}_{4}$ [42.3 mM], $\mathrm{KH}_{2} \mathrm{PO}_{4}$ [22 $\mathrm{mM}$ ], $\mathrm{NaCl}[8.56 \mathrm{mM}], \mathrm{MgSO}_{4}[2 \mathrm{mM}], \mathrm{CaCl}_{2}[0.1 \mathrm{mM}]$, and glucose $[10 \mathrm{mM}]$ ), Brain Heart Infusion Agar and Trypto-Casein Soy Agar were obtained from Sigma Aldrich (Schnelldorf, Germany); tryptic soy broth and Muller-Hinton Agar was obtained from Lab M (England).

\section{Microtiter plate biofilm formation assay}

Biofilm formation was evaluated based on the measurement of the optical density (OD) of biofilms which is in correlation with the biofilm mass developed in microtiter plate wells, after crystal violet staining (Bakke et al., 2001; Djordjevic et al., 2002). The main aim of this investigation was to test the capability of Listeria strains to form biofilms in different stress conditions using the microtiter plate assay (Mouwakeh et al., 2019). For this purpose, Minimal Media M9 was used to assess the biofilm formation of Listeria strains under different sodium chloride $(\mathrm{NaCl})$ concentrations $(0.05,5,10$, and $15 \%)$ and $\mathrm{pH}$ values of 4,5 , and 6 respectively. M9 Minimal media contained water, inorganic salts, and glucose as the sole carbon source. Constant $\mathrm{pH}$ of 4, 5 and 6 were obtained by adding hydrochloric acid ( $\mathrm{HCl} 37 \%$, Sigma Aldrich, USA) or sodium hydroxide (NaOH, Sigma Aldrich, USA) to the M9 Minimal Media. The first step of the microtiter plate assay was the preparation of an overnight culture of Listeria strains on MullerHinton Agar media. The next step was the adjustment of the $\mathrm{OD}_{600}$ of Listeria strains to 0.3 in tubes with Minimal Media M9 using a McFarland densitometer. After that, $200 \mu \mathrm{L}$ of the adjusted strain in M9 was added to each well in the same row of the 96 wells microtiter plates. Similarly, in case of mixed-biofilm experiment, $100 \mu \mathrm{L}$ of the adjusted Listeria pathogenic strain and $100 \mu \mathrm{L}$ of the adjusted Listeria non-pathogenic strain were added to the wells of the microtiter plates. They were then incubated at $37{ }^{\circ} \mathrm{C}$ for $72 \mathrm{~h}$.

The Crystal Violet method was applied for the detection of the total biofilms formed (Mouwakeh et al., 2019). For this purpose, the supernatant of the 96-wells plate was firstly removed and then each well was washed three times with $200 \mu \mathrm{L}$ of phosphate-buffered saline (PBS) before discarding. The formed biomass was stained by adding the Crystal Violet $0.4 \%$ [v/v] to each well and kept at 
room temperature for $15 \mathrm{~min}$. After that, the microtiter plate washing step with PBS was applied again as before and then the plates were dried for $15 \mathrm{~min}$ in a sterile air flow hood. Once dried, 200 $\mu \mathrm{L}$ of acetic acid $33 \%[\mathrm{v} / \mathrm{v}]$ were added to each well followed by the incubation at room temperature for $15 \mathrm{~min}$. The samples from each well $(100 \mu \mathrm{L})$ were then transferred to a sterile microtiter plate and the OD level of the crystal violet present in the solution was measured in a Multiskan Ascent (ThermoLab System) Plate Reader at $595 \mathrm{~nm}$. All experiments were carried out in triplicate.

\section{Statistical analysis}

The significances of the differences between the groups were verified by one-way ANOVA, and the mean comparison were performed by Tukey's test using SPSS-20 software (SPSS Inc., IBM Company, USA). The results were considered significant when $P \leq 0.05$.

\section{RESULTS AND DISCUSSION}

From literature, Listeria strains prefer different temperatures and media when forming biofilms (Pan et al., 2010). However, there is a deficit of studies in the literature showing the biofilm formation of non-pathogenic Listeria strains. According to our results, Listeria ivanovii 204 formed larger quantities of biofilms than the other non-pathogenic Listeria strains when incubated in $\mathrm{M} 9$ Minimal Media at $0.05 \% \mathrm{NaCl}$ concentration (without adjusting $\mathrm{NaCl}$ concentration) at temperature $37{ }^{\circ} \mathrm{C}$ (Fig. 1). Nevertheless, it can be concluded that most of the studied non-pathogenic Listeria strains formed lower amounts of biofilms at the mentioned conditions compared to the pathogenic Listeria monocytogenes \#8 (Fig. 3).

From Fig. 1, the $\mathrm{OD}_{595}$ of the Listeria ivanovii 204 incubated in M9 Minimal Media at $37{ }^{\circ} \mathrm{C}$ with increasing $\mathrm{NaCl}$ concentration from 0.05 to $10 \%$ dropped faster from 0.145 to 0.090 respectively, probably because the bacteria growth was inhibited. When $\mathrm{NaCl}$ concentration is adjusted to $15 \%$, biofilm formation of the Listeria ivanovii 204 did not decrease any further. With the exception of Listeria seeligeri/welshimeri $292(P \leq 0.05)$, all the other strains in the study showed no significant differences of $\mathrm{OD}_{595}$ values at 10 and $15 \% \mathrm{NaCl}$ concentrations.

Similar patterns of biofilm formation $\left(\mathrm{OD}_{595}\right)$ were observed in Listeria innocua CCM4030, Listeria innocua 2885, and Listeria seeligeri/welshimeri 292 when grown on $0.05-15 \% \mathrm{NaCl}$

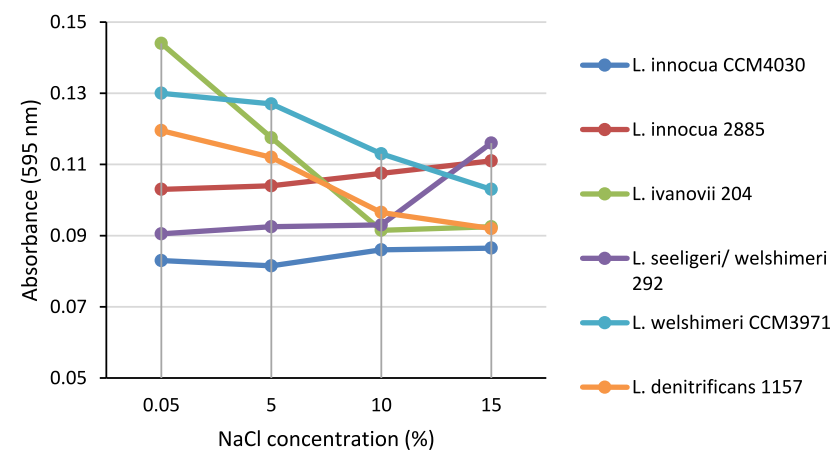

Fig. 1. Biofilm formation $\left(\mathrm{OD}_{595}\right)$ comparison between the studied Listeria strains following $72 \mathrm{~h}$ incubation at $37{ }^{\circ} \mathrm{C}$ under different $\mathrm{NaCl}$ concentrations $(0.05,5,10$, and 15\%) using M9 Minimal Media 
concentrations. A continuously decreasing trend of $\mathrm{OD}_{595}$ was detected for all the other strains, indicating that more biofilm was formed at 0.05 and $5 \%$ than at 10 and $15 \% \mathrm{NaCl}$ concentrations. From these results, it can be concluded that the higher concentrations of $\mathrm{NaCl}$ did not present stress conditions that enhanced biofilm formation from non-pathogenic Listeria strains. Similar results were obtained when biofilm formation of Listeria monocytogenes strains in different $\mathrm{NaCl}$ concentrations were studied (Pan et al., 2010; Xu et al., 2010).

From Fig. 2, all the Listeria strains incubated in M9 Minimal Media at $37{ }^{\circ} \mathrm{C}$ at different $\mathrm{pH}$ values $\left(4,5\right.$, and 6) showed a continuously decreasing trend of $\mathrm{OD}_{595}$, except Listeria ivanovii 204. Therefore, more biofilm amounts were detected at $\mathrm{pH}$ of 6 than at $\mathrm{pH}$ of 4 and 5, respectively, which proves the inhibition effect of acidic conditions for the biofilm formation of Listeria strains.

The lowest amounts of biofilms were observed at $\mathrm{pH} 5$ compared to $\mathrm{pH} 6$ in M9 Minimal Media for all the strains $(P \leq 0.05)$. At $\mathrm{pH} 4$, Listeria ivanovii 204 and Listeria denitrificans 1157 were found to produce the most biofilm thus showing resistance to low $\mathrm{pH}$. The most sensitive strain at $\mathrm{pH} 4$ was Listeria welshimeri CCM3971 that showed weak biofilm formation. At $\mathrm{pH}=$ 5 the lowest amounts of biofilm formed were observed from Listeria ivanovi 204 and Listeria innocua CCM4030, these were the weakest biofilms forming strains.

The biofilm formation (OD 595) from strong biofilm-forming strain Listeria monocytogenes \#8 and its interaction with the weak biofilm forming non-pathogenic Listeria strains, were also studied. Significantly, $(P \leq 0.05)$ more biomass was produced by Listeria monocytogenes $\# 8\left(\mathrm{OD}_{595}=0.251\right.$ $\pm 0.015)$ compared to Listeria innocua $2885\left(\mathrm{OD}_{595}=0.185 \pm 0.02\right)$ and Listeria innocua CCM4030 strains $\left(\mathrm{OD}_{595}=0.182 \pm 0.01\right)$. The $\mathrm{OD}_{595}$ values of the biofilms formed when Listeria monocytogenes \#8 was mixed with the non-pathogenic Listeria strains were significantly $(P \leq 0.05)$ less than that of the biofilms formed by Listeria monocytogenes \#8 only (Fig. 3). Biofilm formation of the strong biofilm-forming Listeria monocytogenes \# 8 was overgrown when mixed with the weak biofilm-forming Listeria innocua 2885 strain among the conditions described above. The same results were also obtained when Listeria monocytogenes \#8 was grown in presence of Listeria innocua CCM4030, thus reducing its biofilm formation. From Fig. 3, the OD 595 values for mixedbiofilm Listeria monocytogenes \#8 with Listeria innocua 2885 strain were significantly $(P \leq 0.05)$ lower compared to mixed-biofilm Listeria monocytogenes \#8 with Listeria innocua CCM4030 strain.

The same inhibition phenomenon was obtained from the studies of Noorwoord and Gilmour (2001) and Rodríguez-López et al. (2015) where a decrease in Listeria monocytogenes

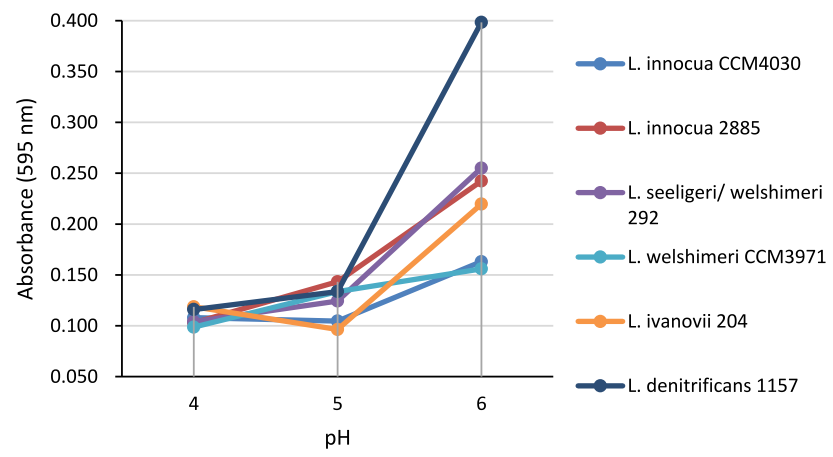

Fig. 2. Biofilm formation $\left(\mathrm{OD}_{595}\right)$ comparison between the studied Listeria strains following $72 \mathrm{~h}$ incubation at $37{ }^{\circ} \mathrm{C}$ under different $\mathrm{pH}$ values $(4,5$ and 6) using M9 Minimal Media 


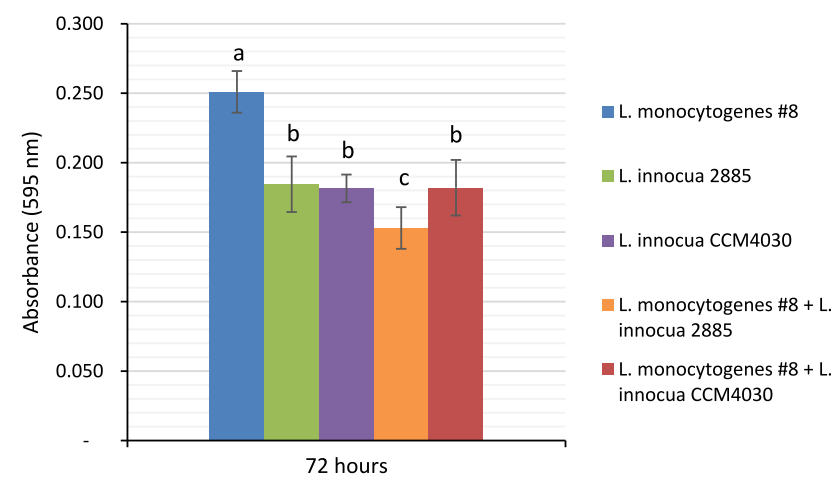

Fig. 3. Biofilm formation of Listeria monocytogenes $\# 8$ and its mixed biofilm formation with Listeria innocua 2885 and Listeria innocua CCM4030 following $72 \mathrm{~h}$ incubation at $37^{\circ} \mathrm{C}$ using M9 Minimal Media. Error bars represent the standard deviations of the means, from three individual measurements. Different letters above the bars indicate a significant difference $(P \leq 0.05)$

cell numbers was observed in multispecies biofilms formed with Staphylococcus xylosus, Pseudomonas fragi, and Carnobacterium divergens comparing with Listeria monocytogenes cell numbers grown in monocultures. Habimana et al. (2011) obtained similar results on prevention of Listeria monocytogenes subsequent biofilm formation by the presence of a technological flora resident namely Lactoccocus lactis, due to competition for adhesion sites. The studies of Zhao et al. $(2006,2013)$ have shown promising results on the use of Lactoccocus lactis against Listeria monocytogenes biofilm in food facility-testing. Contrarily, other studies showed a strong effect that the microorganisms present in food facilities can play on the number of adhered cells of Listeria monocytogenes in the biofilm. This can correspond to either mixed biofilm enhancement or inhibition (Carpentier and Chassaing, 2004; Fox et al., 2014). Nevertheless, a recent study by Tan et al. (2019) proved that the composition and diversity of microbiota from food processing surfaces indicates the persistence of the Listeria monocytogenes. This reiterates the need for further investigation on microbiota characterization particularly, on the role of the harmless bacteria in the food safety.

\section{CONCLUSIONS}

After studying growth conditions of non-pathogenic Listeria strains, higher concentrations of sodium chloride did not present a stress condition that enhanced biofilm formation. Decrease in $\mathrm{pH}$ however, exhibited some inhibition effect for biofilm formation in all of the non-pathogenic Listeria strains. The results also showed that the biofilm formation of the strong biofilm-forming Listeria monocytogenes \#8 was overgrown when mixed with the weak biofilm-forming Listeria strains. Biofilm inhibition was 17.5 and $39.1 \%$ for Listeria monocytogenes \#8, when it was grown in the presence of Listeria innocua CCM4030 or Listeria innocua 2885 non-pathogenic strains. The future perspective of these findings is the use of potential non-pathogenic strains of Listeria as biocontrol in the food industry. Therefore, biofilm formation of the pathogenic Listeria could be inhibited by the application of non-pathogenic strains on the food processing facilities as a 
part of sanitation procedures. However, further investigation on the biofilm formation of Listeria strains and their interaction under different environmental conditions is still necessary. Their antagonistic effects could provide more information on conditions that may inhibit biofilm formation and could further be used to control the production of Listeria monocytogenes biofilms in the food industry.

\section{ACKNOWLEDGMENT}

The Project was supported by the European Union and co-financed by the European Social Fund (grant agreement no. EFOP-3.6.3-VEKOP-16-2017-00005).

\section{REFERENCES}

Bajovic, B., Bolumar, T., and Heinz, V. (2012). Quality considerations with high pressure processing of fresh and value added meat products. Meat Science, 92(3): 280-289.

Bakke, R., Kommedal, R., and Kalvenes, S. (2001). Quantification of biofilm accumulation by an optical approach. Journal of Microbiological Methods, 44(1): 13-26.

Carpentier, B. and Chassaing, D. (2004). Interactions in biofilms between Listeria monocytogenes and resident microorganisms from food industry premises. International Journal of Food Microbiology, 97(2): 111-122.

Dalmadi, I., Kántor, D., Wolz, K., Polyák-Fehér, K., Pásztor-Huszár, K., Farkas, J., and Fekete, A. (2007). Instrumental analysis of strawberry puree processed by high hydrostatic pressure or thermal treatment. Progress in Agricultural Engineering Sciences, 3(1): 47-66.

Di Ciccio, P., Conter, M., Zanardi, E., Ghidini, S., Vergara, A., Paludi, D., Festino, A.R., and Ianieri, A. (2012). Listeria monocytogenes: biofilms in food processing. Italian Journal of Food Science, 24(3).

Djordjevic, D., Wiedmann, M., and McLandsborough, L.A. (2002). Microtiter plate assay for assessment of Listeria monocytogenes biofilm formation. Applied and Environmental Microbiology, 68(6): 2950-2958.

Fox, E.M., Solomon, K., Moore, J.E., Wall, P.G., and Fanning, S. (2014). Phylogenetic profiles of in-house microflora in drains at a food production facility: comparison and biocontrol implications of Listeriapositive and-negative bacterial populations. Applied and Environmental Microbiology, 80(11): 33693374.

Habimana, O., Guillier, L., Kulakauskas, S., and Briandet, R. (2011). Spatial competition with Lactococcus lactis in mixed-species continuous-flow biofilms inhibits Listeria monocytogenes growth. Biofouling, 27(9): 1065-1072.

Martín, B., Perich, A., Gómez, D., Yangüela, J., Rodríguez, A., Garriga, M., and Aymerich, T. (2014). Diversity and distribution of Listeria monocytogenes in meat processing plants. Food Microbiology, 44: 119-127.

Mouwakeh, A., Kincses, A., Nové, M., Mosolygó, T., Mohácsi-Farkas, C., Kiskó, G., and Spengler, G. (2019). Nigella sativa essential oil and its bioactive compounds as resistance modifiers against Staphylococcus aureus. Phytotherapy Research, 33(4): 1010-1018.

Norwood, D.E. and Gilmour, A. (2001). The differential adherence capabilities of two Listeria monocytogenes strains in monoculture and multispecies biofilms as a function of temperature. Letters in Applied Microbiology, 33(4): 320-324. 
Pan, Y., Breidt, F., and Gorski, L. (2010). Synergistic effects of sodium chloride, glucose, and temperature on biofilm formation by Listeria monocytogenes serotype $1 / 2 \mathrm{a}$ and $4 \mathrm{~b}$ strains. Applied and Environmental Microbiology, 76(5): 1433-1441.

Renner, L.D. and Weibel, D.B. (2011). Physicochemical regulation of biofilm formation. MRS Bulletin, 36(5): 347-355.

Rodríguez-López, P., Saá-Ibusquiza, P., Mosquera-Fernández, M., and López-Cabo, M. (2015). Listeria monocytogenes-carrying consortia in food industry. Composition, subtyping and numerical characterisation of mono-species biofilm dynamics on stainless steel. International Journal of Food Microbiology, 206: 84-95.

Rückerl, I., Muhterem-Uyar, M., Muri-Klinger, S., Wagner, K.H., Wagner, M., and Stessl, B. (2014). L. monocytogenes in a cheese processing facility: learning from contamination scenarios over three years of sampling. International Journal of Food Microbiology, 189: 98-105.

Tan, X., Chung, T., Chen, Y., Macarisin, D., LaBorde, L., and Kovac, J. (2019). The occurrence of Listeria monocytogenes is associated with built environment microbiota in three tree fruit processing facilities. Microbiome, 7(1), p.115.

Van Houdt, R. and Michiels, C.W. (2010). Biofilm formation and the food industry, a focus on the bacterial outer surface. Journal of Applied Microbiology, 109(4): 1117-1131.

$\mathrm{Xu}, \mathrm{H}$., Zou, Y., Lee, H.Y., and Ahn, J. (2010). Effect of $\mathrm{NaCl}$ on the biofilm formation by foodborne pathogens. Journal of Food Science, 75(9): M580-M585.

Zaukuu, J.L.Z., Oduro, I., and Ellis, W.O. (2016). Processing methods and microbial assessment of pito (an African indigenous beer), at selected production sites in Ghana. Journal of the Institute of Brewing, 122(4): 736-744.

Zhao, T., Podtburg, T.C., Zhao, P., Chen, D., Baker, D.A., Cords, B., and Doyle, M.P. (2013). Reduction by competitive bacteria of Listeria monocytogenes in biofilms and Listeria bacteria in floor drains in a ready-to-eat poultry processing plant. Journal of Food Protection, 76(4): 601-607.

Zhao, T., Podtburg, T.C., Zhao, P., Schmidt, B.E., Baker, D.A., Cords, B., and Doyle, M.P. (2006). Control of Listeria spp. by competitive-exclusion bacteria in floor drains of a poultry processing plant. Applied and Environmental Microbiology, 72(5): 3314-3320.

Open Access. This is an open-access article distributed under the terms of the Creative Commons Attribution 4.0 International License (https://creativecommons.org/licenses/by/4.0/), which permits unrestricted use, distribution, and reproduction in any medium, provided the original author and source are credited, a link to the CC License is provided, and changes - if any - are indicated. (SID_1) 